- The data generated provide a useful baseline for the provision of preventive care in Wales at a time of contract change.

- The study findings highlight the barriers to the provision of preventive care under the current system.

- This article provides an insight into the attitudes of general dental practitioners to the provision of health education versus health promotion.

\title{
Provision of prevention to adults in NHS dental practices and attitudes to prevention
}

\author{
P. Tomlinson ${ }^{1}$ and E. Treasure ${ }^{2}$
}

\begin{abstract}
Aims To identify the number of claims reported by the Dental Practice Board (DPB) for the three adult preventive codes for the year ending October 2002 in Wales. To identify the attitudes of practitioners to the use of these codes.
\end{abstract}

Design A cross-sectional study using routinely gathered DPB data and data generated by a postal questionnaire.

Sample All DPB claims for the 12 months ending October 2002. A randomised sample of 400 dentists currently practising in Wales for the postal questionnaire.

Results The DPB data showed great variation across Wales for: the number, type and distribution of preventive code claims; the age and payment status of patients prescribed these treatments; and the proportion of male versus female dentists claiming for the codes. The questionnaire response rate was $67 \%(n=267)$. The results showed that most respondents were deterred by the restrictions on the codes, insufficient reimbursement and a perceived unwillingness of patients to pay for preventive care.

Conclusion Few dentists provide preventive care to adults under the existing remuneration system. Work is necessary to enable dentists to use effective preventive techniques for adult patients.

These results can be considered to show the baseline provision of prevention and could facilitate the evaluation of any changes to the current system.

\section{INTRODUCTION}

Despite the fact that the majority of oral disease is preventable, dental services in the UK currently focus primarily on the conservative management of existing disease.

In the current policy environment, ${ }^{1}$ it is essential to understand the reasons why general dental practitioners have or have not adopted preventive practices. Lessons learned from the previous system should provide the foundation of any future proposals.

\footnotetext{
${ }^{1 *}$ Clinical Lecturer, ${ }^{2}$ Professor in Dental Public Health, The Dental School, Cardiff University, Heath Park, Cardiff, CF14 4XY

${ }^{*}$ Correspondence to: Miss Pamela Tomlinson

Email: tegfedd@hotmail.com
}

\section{Refereed paper}

Accepted 13 April 2005

doi: $10.1038 /$ sj.bdj.4813425

๑ British Dental Journal 2006; 200: 393-397
In the present system's Statement of Dental Remuneration ${ }^{2}$ (SDR), three codes are intended to meet the need for NHS preventive care amongst adult patients. This study sought to identify the number of claims reported by the Dental Practice Board (DPB) for these codes for the year ending October 2002.

It is not known what the current level of prescribing of prevention is and little is known regarding practitioners' attitudes to prevention in practice, as previous studies have mainly focused on individual factors such as smoking cessation. However, the changes proposed for the General Dental Services in England and Wales ${ }^{1,3}$ are supposed to increase the amount of prevention provided to adults. Indeed, one of the suggested aims of a new contract is to 'allow the dental team, for the first time, to focus on preventive measures to combat dental disease. ${ }^{1}$

It is therefore essential to know from where we are starting. The aims of this study were to establish the current level of provision of reimbursed preventive care to adult NHS patients in Wales and to determine the reasons why dentists do or do not claim payment for providing such care.

\section{METHOD}

The study was a two-part cross-sectional design. The first part of the study concerned data generated by a postal questionnaire issued to dentists which comprised closed questions, with the opportunity to give multiple responses.

The sampling frame comprised all dentists in Wales who were in general dental practice at the time of sample selection $(1,021)$. A randomised sample of 400 (39.2\%) dentists was selected by a researcher at the Dental Practice Board (DPB) using a random number generator to reduce the risk of selection bias. The sample was representative of the population of dentists in Wales by gender and age group.

Following a pilot study, the questionnaire was amended and issued in April 2003 and reissued to non-responders in May 2003. This was conducted by the DPB to avoid passing dentists' details to a third party and to ensure the anonymity of respondents.

The second part of the study used data routinely collected by the DPB for claims made in Wales for the three SDR codes relating to adult preventive care. The fee, description and restrictions for each code can be found in Table 1 . The most recent complete year for which the DPB data were available at the time of the study ended October 2002. For the prescribing dentist age and gender, and for patient age and payment status (ie exempt or not from NHS 


\begin{tabular}{|c|c|c|c|}
\hline Code & Fee & Requirements & Restrictions \\
\hline 0601 & $£ 7.25$ & $\begin{array}{l}\text { Intensive instruction in the prevention of dental disease, } \\
\text { including advice on diet and on oral hygiene techniques, } \\
\text { and normally requiring more than one visit per course } \\
\text { of treatment. }\end{array}$ & $\begin{array}{l}\text { No fee under this item shall be payable where a fee } \\
\text { under this item or for topical fluoride or periodontal } \\
\text { treatment*has been paid, or is payable, to the same } \\
\text { dentist for treatment provided during the previous five calendar } \\
\text { months complete in the same or a previous course of treatment }\end{array}$ \\
\hline 0701 & $€ 6.55$ & $\begin{array}{l}\text { Application of fissure sealants as a primary preventive } \\
\text { measure to pits and fissures, normally of unfilled third } \\
\text { molar teeth within two years of their eruption. }\end{array}$ & \\
\hline 0711 & $£ 31.10$ & $\begin{array}{l}\text { Application of topical fluoride preparations to all teeth } \\
\text { for patients who, because of their exceptional medical } \\
\text { or dental conditions or because of their behavioural or } \\
\text { habitual problems, show evidence of a high risk of rapidly } \\
\text { advancing dental caries. Treatment normally requiring } \\
\text { not less than three visits. }\end{array}$ & $\begin{array}{l}\text { A fee for this item shall only be payable in connection with } \\
\text { treatment under items } 10(a, b, c) \neq \text { or where a fee under items } \\
10(a, b, c) \neq \text { is payable or has been paid to previous three complete } \\
\text { calendar months, except where such treatment under this item } \\
\text { is provided on referral. } \\
\text { No fee shall be paid under this item where the same dentist has } \\
\text { been paid, or is entitled to be paid, a fee for treatment provided } \\
\text { under this item during the previous five complete calendar months. }\end{array}$ \\
\hline
\end{tabular}
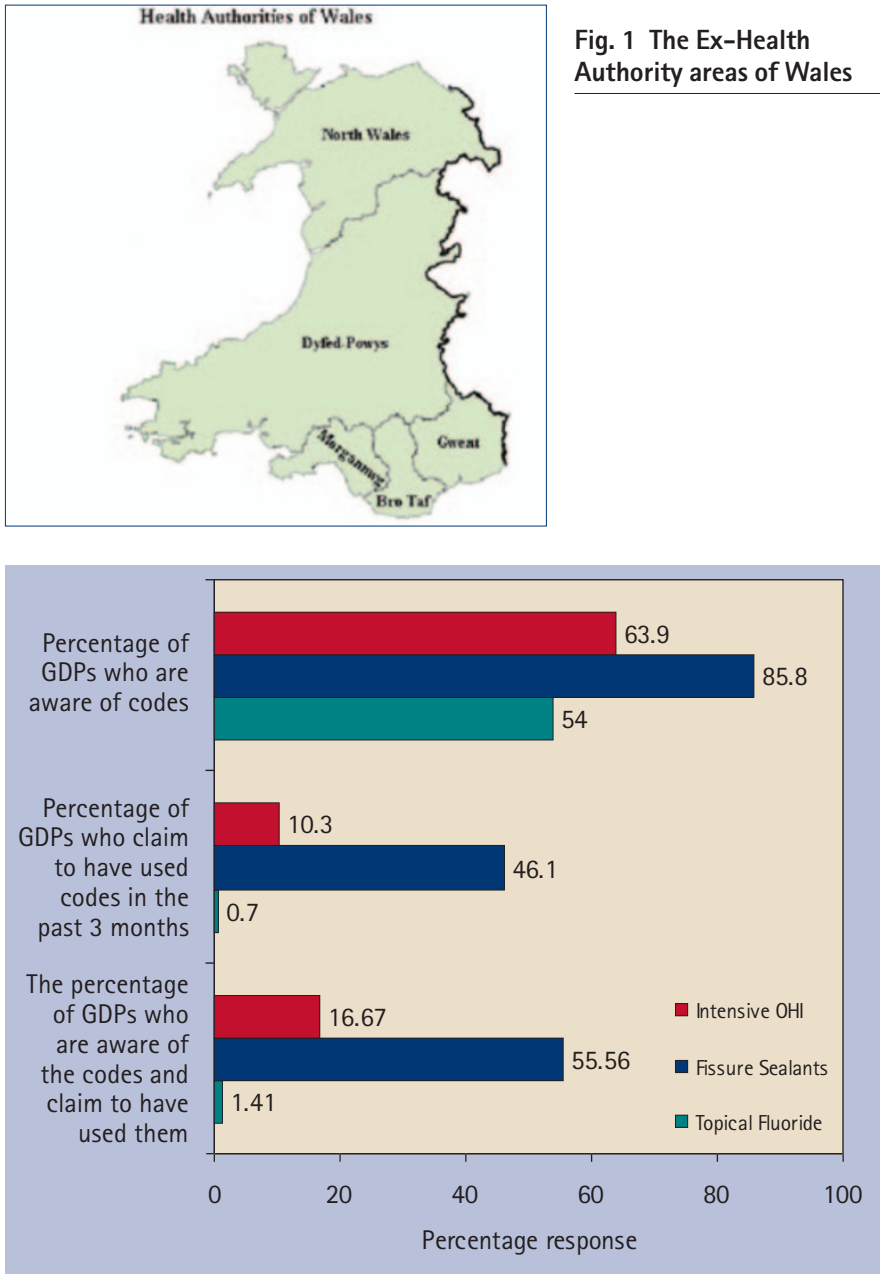

Fig. 2 The number of respondents who are aware of and say they claim for the preventive codes 0601,0701 and 0711 , and the proportion of the total number of respondents (263) who are aware of and say they claim for these codes. Multiple responses were possible.

charges), the data were provided by ex-Health Authority areas (Fig. 1), as this was the recording geography at that time.

\section{RESULTS}

Of the 400 questionnaires issued, 267 were returned, giving a response rate of $67 \%$ after one reissue of the questionnaire.

Of the three preventive codes, dentists were apparently more aware of 0701, Fissure Sealants, and least aware of 0711, Topical Fluoride. Despite over 50\% of respondents being aware of each code (Fig. 2), few had claimed for them in the past three months.
No statistically significant difference was found between those respondents who claimed to use the preventive codes and those who did not claim to do so, with respect to practice size or access to the services of a hygienist.

The factors which most commonly deterred the respondents from claiming the preventive codes were insufficient reimbursement (56.1\%) and too many restrictions on the codes (54.2\%). Only $5.2 \%$ of the respondents felt that there was no need to provide preventive care to adult NHS patients (Fig. 3).

The preferred form of NHS remuneration was fee-per-item with fewer restrictions for claims (49.4\%), with only 4.4\% believing that the current system was adequate. Opinion was evenly divided on the merits of a registration fee based on the care required at the first appointment (31.7\%) and a supplementary fee based on the postcode (29.9\%) (Fig. 4).

The respondents considered that oral hygiene instruction was the most appropriate form of health promotion for dentists to provide (94.5\%), followed by instruction in the use of fluorides $(88.2 \%)$ and dietary advice concerning low sugar and erosive foods only (84.9\%) (Fig. 5).

More dentists were open to providing smoking cessation advice to patients (59.4\%) than to instructing patients on a diet for general health (51.3\%). Only 21.0\% felt it was appropriate to provide health promotion concerning drug and alcohol addiction (Fig. 5).

However, the analysis of the routine DPB data showed that there were low numbers of claims for all three codes, with great variety of prescribing patterns amongst the five ex-Health Authority areas (Fig. 6).

The age distribution of prescribing dentists matched that of all dentists in Wales. The proportion of claiming male or female dentists varied widely between ex-Health Authority areas.

There was a higher rate of claims for all codes for exempt patients, with more claims for the younger age groups. There was a similar age presentation for non-exempt patients, except for Intensive $\mathrm{OHI}$ which peaked at age 45-64 years (Fig. 7).

A comparison of the number of examinations conducted in each area during the same period of time emphasised the low number of episodes of preventive care provided. It also showed up to a 20 -fold variation between the ex-Health Authority areas in the proportion of examinations that resulted in an episode of preventive care (Table 2).

\section{DISCUSSION}

The data provided by the DPB confirmed that few dentists in Wales claimed for the three codes (Fig. 6), and that a negligible proportion of examinations resulted in their prescription (Table 2). The questionnaire results only provide the views of a 
proportion of Welsh dentists due to the size of the response rate and the inherent response bias.

\section{Location, location, location}

There was considerable variation in prescription of the codes across Wales. The highest proportion of prescribing dentists and the greatest number of claims were from the most rural areas of the country, Dyfed Powys and North Wales (Fig. 6). Indeed, there was a 20-fold difference in the number of examinations resulting in preventive care between rural Dyfed Powys and urban Iechyd Morgannwg (Table 2). An Australian study ${ }^{4}$ found that patients in rural areas received less prevention than those in urban areas, but it related to private provision, whereas this study addressed only NHS care. It is possible that in Welsh urban centres, the high disease levels and demand for treatment may leave no time for the provision of prevention, as $\mathrm{Chen}^{5}$ found that 'patient load correlated negatively with dentists' delivery of prevention'. In rural areas, patients may be more willing to pay for prevention if access to dental emergency care is a problem due to location. Also, in areas with few dentists, the presence of one or more dentists with unusual prescribing patterns can have a proportionately larger impact on the area's claims profile.

\section{The impact of patient payment status}

Higher social status has been linked to receptivity to prevention, yet more prevention was provided to exempt patients, suggesting targeted prevention. Treasure et al. ${ }^{6}$ found that 'variations in [adult] disease are caused by more than social class structure', but certain behaviours are associated with social class. Lower socio-economic groups have a positive association with smoking $^{7}$ and are less likely to be regular dental attenders. ${ }^{6}$

Alternatively, the data may confirm the findings of the questionnaire, where dentists were deterred from providing prevention by a perceived reluctance of patients to pay (Fig. 3), or perhaps the higher numbers of young, exempt patients receiving preventive care may not reflect the social status of these individuals. Women are exempt from payments during pregnancy and dentists may take the opportunity to provide preventive care that the patient would normally have to pay for.

\section{Questionnaire findings}

The number of respondents who said they claimed for code 0701 in the previous three months was 10 times the actual number of claims for a similar period. This suggests confusion between the brief description '0701: fissure sealants' in the questionnaire and the SDR codes 1441-1444 'sealants and sealant restorations'.

Despite this misunderstanding, the results of the postal survey showed that awareness of the opportunity to claim for preventive care does not in itself lead to claims (Fig. 2), although previous work $^{8}$ suggested that dentists believed prevention to be more cost effective than operative dentistry.

One in 20 (5.2\%) of the respondents felt prevention to be unnecessary for adults. The DPB data suggested that the mean proportion of dentists claiming for prevention in Wales was only 11.5\%, giving a discrepancy of 83.3\% who advocate it but either do not provide it or do not use existing codes to claim reimbursement.

The questionnaire attempted to discover if potential facilitators to the provision of prevention existed, and similarly with deterrents. However, data limitation prevented direct comparison between the practice profiles generated by the questionnaire responses and the data provided by the DPB.

\section{Possible facilitators}

An American study ${ }^{5}$ found a positive correlation between the presence of a hygienist and the provision of prevention and almost half of the respondents without a hygienist claimed that

\begin{tabular}{|c|c|c|c|c|}
\hline Ex-Health Authority Area & $\begin{array}{l}\text { Number of examinations } \\
(1 \mathrm{a}, 1 \mathrm{~b}, 1 \mathrm{c})\end{array}$ & $\begin{array}{l}\text { Number of episodes of } \\
\text { preventive care } \\
(0601,0701,0711)\end{array}$ & $\begin{array}{l}\% \text { of examinations resulting } \\
\text { in preventive care }\end{array}$ & $\begin{array}{l}\text { Ratio of preventive } \\
\text { care episodes to } \\
\text { examinations }\end{array}$ \\
\hline North Wales & 285956 & 156 & 0.05 & $1: 1833$ \\
\hline lechyd Morgannwg & 258720 & 26 & 0.01 & $1: 9951$ \\
\hline Gwent & 234496 & 129 & 0.06 & $1: 1818$ \\
\hline Dyfed Powys & 187865 & 373 & 0.2 & $1: 504$ \\
\hline Bro Taf & 313689 & 113 & 0.04 & $1: 2776$ \\
\hline All Wales & 1280726 & 797 & 0.06 & $1: 1606$ \\
\hline
\end{tabular}

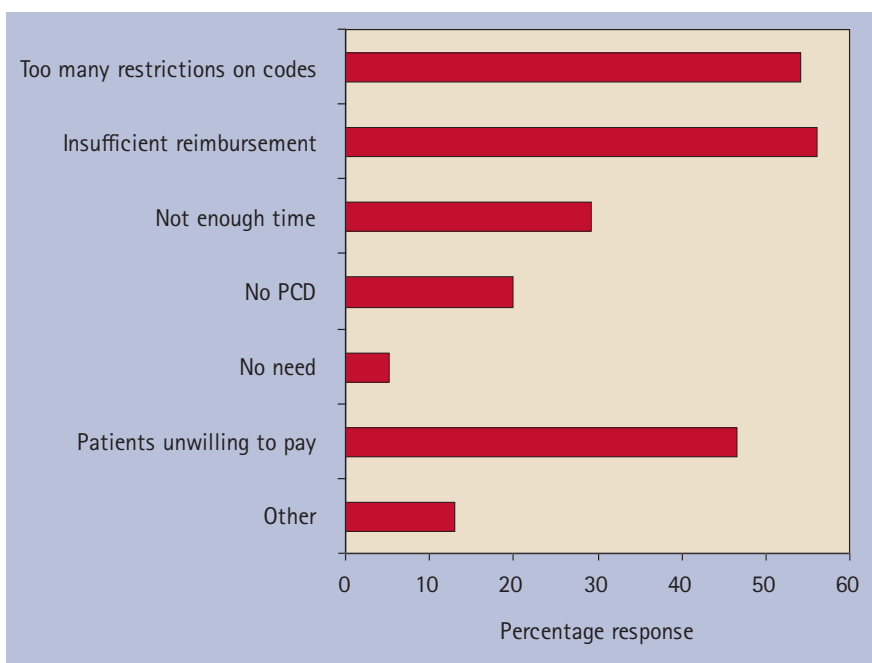

Fig. 3 The percentages of the reasons why respondents are deterred from claiming codes $0601,0701,0711$. Multiple responses possible.

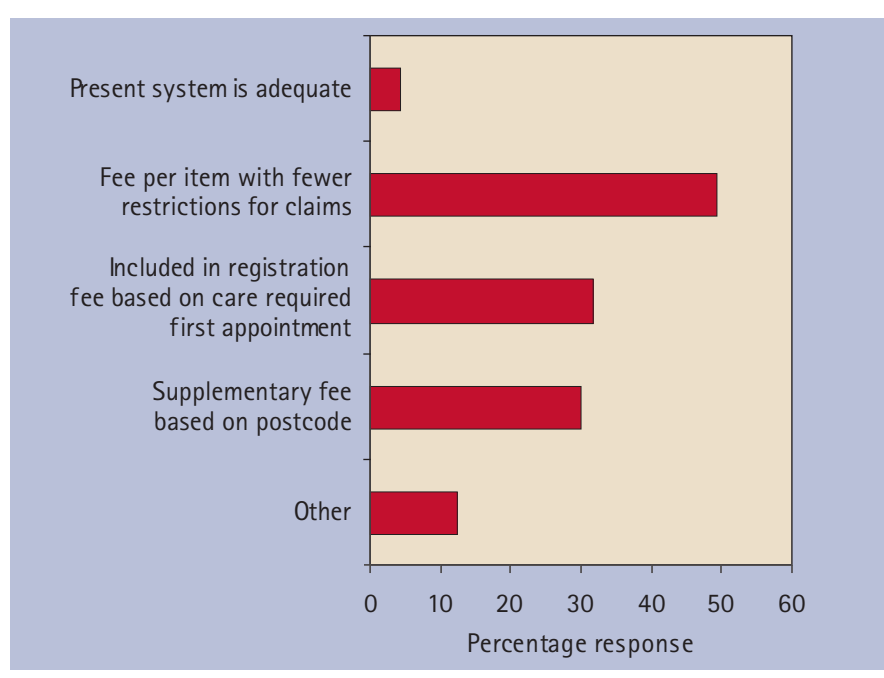

Fig. 4 The percentage for the preferred form of remuneration of respondents for preventive care. Multiple responses possible. 


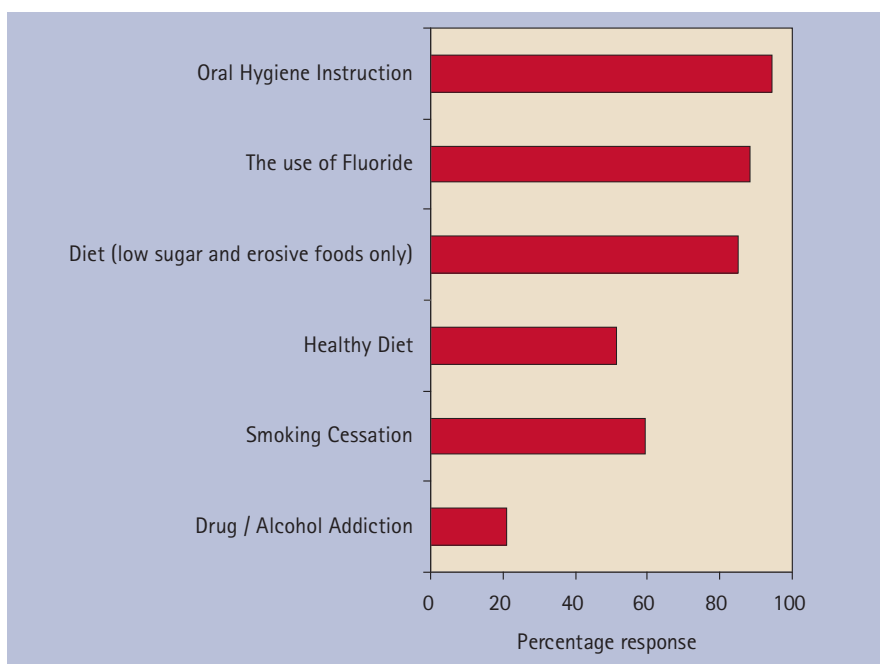

Fig. 5 The number and percentage of respondents who consider each health promotion topic to be appropriate for dentists. Multiple responses possible.

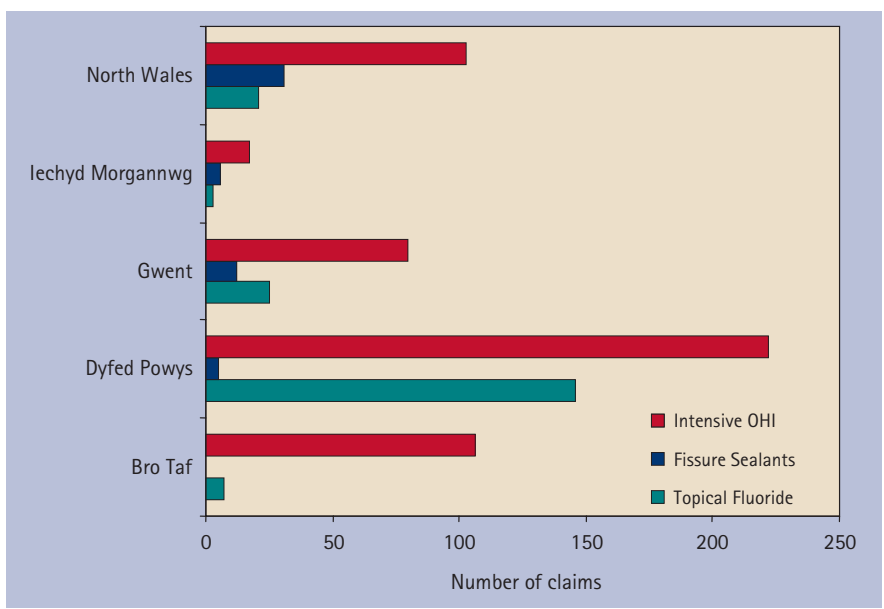

Fig. 6 The distribution of claims for each SDR preventive code by ex-Health Authority area for patients aged 18 and over, 2002

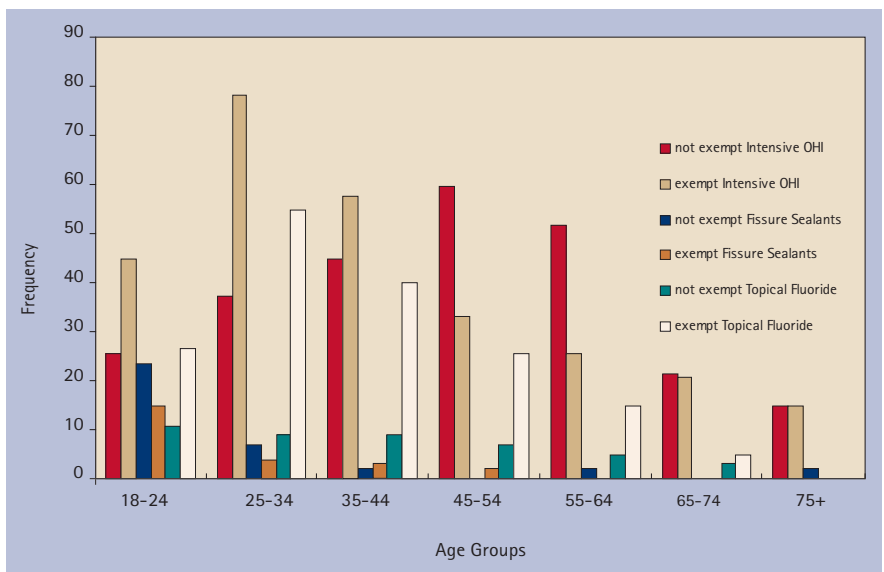

Fig. 7 The numbers of exempt and not-exempt patients by age group who received each of the three preventive treatments.

this stopped them from providing prevention (Fig. 3). However, there was no difference between the proportions of respondents with or without a hygienist who claimed to provide prevention, as found previously in the UK. ${ }^{8}$

Respondents' comments suggested that 'access to a hygienist' may mean as little as one session per week between several dentists. This may in part explain why there was no difference in the amount of prevention claimed to be provided by dentists in large or small practices, and perhaps some larger practices have used their available facilities to recruit a dentist rather than a hygienist.

\section{Possible deterrents}

In this study, 56.1\% of respondent dentists claimed that insufficient remuneration deterred them from providing prevention. McCann et al. ${ }^{9}$ found that $40 \%$ of respondent dentists were deterred from providing smoking cessation advice because there was no remuneration at all.

However, fewer respondents complained of lack of time (29.2\%) than in smoking cessation studies $\left(43 \%,{ }^{9} 49.6 \%{ }^{10}\right)$.

Perhaps recent uncertainties in the NHS dental service focussed respondents towards fees and restrictions, as the latter deterred $54.2 \%$ of respondents, particularly for Intensive $\mathrm{OHI}$.

In the study by John et al., ${ }^{11}$ private dentists were more likely to provide smoking cessation advice $(p=0.002)$ than NHS dentists, suggesting that certain patients were willing to pay for prevention. In this study, perceived patient reluctance to pay for prevention was highlighted by $46.5 \%$ of respondents as a deterrent (Fig. 3).

Only $4.4 \%$ of respondents in this study felt that the current remuneration system was adequate. The preferred remuneration system for approximately half of the respondents was fee-peritem (as found previously ${ }^{12}$ ) but with fewer restrictions on the codes. The absence of a salaried option may have influenced the response (Fig. 4).

\section{CONCLUSIONS}

This study has found that the main barrier to the provision of preventive care to adult NHS patients relates to finances. This appears to be primarily because dentists feel inadequately reimbursed for providing such care, and secondarily because they make assumptions about the type of treatment that their patients are willing to pay for.

In addition, the findings suggest that the complexity and restrictions of the current reimbursement system also inhibit the provision of prevention to adults and it is hoped that future changes to the dentists' contract will provide greater encouragement and opportunities for the provision of such care.

However, it will take more than just an increase in fees to improve the situation. Many dentists appear unwilling to adopt new strategies such as the common risk factor approach, preferring instead to continue with basic oral health education irrespective of its impact on patients' general health. It appears that many dentists need to be educated and convinced of the benefits of health promotion before they have the necessary information to provide appropriate advice to their patients.

Recommendations:

1. Allocating money and time within any new contract for the promotion of prevention with, if necessary, a tick box for patients to sign indicating receipt of advice.

2. Agreeing worthwhile treatments with fewer restrictions on their provision.

3. Educating dentists about common risk factors and health promotion.

4. Ensuring that all practices have a point of referral for smoking cessation support.

The authors would like to thank Raymond Tongue, Head of External Projects for the Dental Practice Board, without whose timely assistance and support this study could not have been undertaken.

1. Department of Health. NHS dentistry: Options for change. London: HMSO, 2002

2. Department of Health. The statement of dental remuneration: amendment 89. Distributor: Dental Practice Board, Eastbourne, 2002.

3. Welsh Assembly Government. Improving health in Wales: Routes to reform. Cardiff: Welsh Assembly Government, 2002.

4. Brennan D S, Spencer A J. Provision of diagnostic and preventive services in general dental practice. Comm Dent Health 2003; 20: 5-10.

5. Chen M S. Preventive dentistry in Texas, USA. Comm Dent Oral Epidemiol 1990 
18: $239-243$.

6. Treasure $E$, Kelly $M$, Nuttall $N$ et al. Factors associated with oral health: a multivariate analysis of results from the 1998 Adult Dental Health Survey. Br Dent 2001; 190: 60-68.

7. Office of National Statistics: Social Survey Division. Living in Britain: results from the 1998 General Household Survey. London: Office of National Statistics, 1999.

8. Holloway $\mathrm{P} J$, Ashton $\mathrm{M} \mathrm{A}$, Wainwright-Stringer $\mathrm{Y}$, Worthington $\mathrm{H}$ V. Preventive technologies in dental practice in the UK. Int Dent J 1997; 47: 271-274.

9. Mccann M F, MacPherson L M, Binnie VI, Stephen K W. A survey of Scottish primary care dental practitioners' oral cancer-related practices and training requirements. Comm Dent Health 2000; 17: 24-34.

10. Chestnutt I G, Binnie V I. Smoking cessation counselling - a role for the dental profession? Br Dent J 1995; 179: 411-415.

11. John J H, Yudkin P, Murphy $M$ et al. Smoking cessation interventions for dental patients - attitudes and reported practices of dentists in the Oxford region. Br Dent 1997; 183: 359-364.

12. Nuttall N M, Pitts N B. Scottish dentists' preferences for remuneration and their opinions on the scope of General Dental Service treatment. Br Dent J 1989; 166: 451-454. 